\title{
Association between Dietary Habits and Body Mass Index to Female Students College Sciences and Arts Campus 1 at Khamis Mushayt King Khalid University
}

\author{
Bothaina Abd El Hakeem ${ }^{*}$, Sraa Abu-Melha², Nanees Gad1, Mona Alsheri1 \\ ${ }^{1}$ Department of Public Health, College of Applied Medical Sciences, King Khalid University, Khamis Mushayt, KSA \\ ${ }^{2}$ Department of Chemistry, Faculty of Science, King Khalid University, Abha, KSA \\ Email: ${ }^{\text {bothaina 2007@yahoo.com }}$
}

Received 29 March 2015; accepted 27 October 2015; published 30 October 2015

Copyright (C) 2015 by authors and Scientific Research Publishing Inc.

This work is licensed under the Creative Commons Attribution International License (CC BY).

http://creativecommons.org/licenses/by/4.0/

(c) (i) Open Access

\begin{abstract}
Background: In the Kingdom of Saudi Arabia (KSA), recent studies revealed increasing consumption of animal products and refined foods in the diet at the expense of vegetables and fruits. These dietary changes were accused of increasing the prevalence of both overweight and obesity observed among Saudi children, adolescences and adults in the last few decades. Objectives: The present study was a cross sectional study aimed at exploring the BMI distribution among students of college of Sciences and Arts for girls Khamis Mushayt Campus 1 at King Khalid University (KKU) and investigated how Dietary habits of students female affected body mass index (BMI). Methods: A total of 240 female students aged 18 - 22 years were about $25 \%$ from total students randomly chosen from college of Arts and Science Campus 1 at Khamis Mushayt, King Khalid University, KSA for the present study. A self-reported questionnaire about the student's dietary habits was conducted and their body mass index (BMI) was measured. Data were analyzed using SPSS statistical software and Chi-square test conducted for variables. Results: About half of the students (47\%) were within normal weight, $27.4 \%$ were under weight, $16 \%$ were overweight and $9.6 \%$ were categorized obese. The majority of the students reported eating meals with their family while more than half of sample (58.7\%) had eating meals during watching TV. It was worth mentioning that 84.5\% of students reported eating snacks such as chocolate and chips 3 or more times per week. There were no significant differences between BMI category and dietary habits. Conclusion and Recommendations: There were no significant difference between body mass index category and dietary habits. Increasing educational programs introduced healthy dietary concepts to improve the dietary habits of female students.
\end{abstract}

"Corresponding author.

How to cite this paper: El Hakeem, B.A., Abu-Melha, S., Gad, N. and Alsheri, M. (2015) Association between Dietary Habits and Body Mass Index to Female Students College Sciences and Arts Campus 1 at Khamis Mushayt King Khalid University. Food and Nutrition Sciences, 6, 1316-1323. http://dx.doi.org/10.4236/fns.2015.614137 


\section{Keywords}

\section{BMI, Female Obesity, Dietary Habits}

\section{Introduction}

Obesity results from an imbalance between energy intake and energy expenditure. Relative excessive energy intake can of course result from excess fat intake. Because diets high in fat are usually energy dense and palatable, a diet relatively high in fat usually leads to an increase in energy intake [1].

BMI used only for measuring obesity and using it instead of measures of body composition (e.g. percentage body fat), or body fat distribution (e.g. waist circumference or waist-hip ratio) may result in misclassification. For example, mortality was linearly associated with the ratio between fat-free body mass and body fat-mass, whereas BMI was related to mortality in a U-shaped relation [2].

In 2013, world health organization (WHO) reported that 42 million children under the age of 5 were overweight or obese. Once considered as a high-income country problem, overweight and obesity are now on the rise in low- and middle-income countries, particularly in urban settings. In developing countries with emerging economies (classified by the World Bank as lower- and middle-income countries), the rate of increase of childhood overweight and obesity has been more than $30 \%$ higher than that of developed countries [3].

Overweight and obesity are linked to more deaths worldwide than underweight. Most of the world's population lives in countries where overweight and obesity kill more people than underweight (this includes all highincome and most middle-income countries) [3].

The present study is a cross sectional descriptive study aimed at exploring the BMI distribution among students of college of arts and science for girls Khamis Mushyat Campus 1 at King Khalid University (KKU) and how dietary habits of students female affect body mass index (BMI), which may be an indicator of future weight gain and estimate the prevalence of overweight and obesity among female students.

\section{Sampling and Methods}

A cross section study was conducted in college of Sciences and Arts for girls Khamis Mushyat Campus 1 at King Khalid University (KKU) of 2014. The sample size of this study was calculated based on the precision of study (Equation (1)) [4]

$$
n=(1.96)^{2} \times 0.2 \times 0.78 /(0.025)^{2}=240
$$

The students aged $18-22$ years had participated in the study. All of the participants were Kingdom of Saudi Arabia chosen by randomly sampling method by number registration and name of student.

\section{Data Collection}

Body weight was recorded to the nearest $0.2 \mathrm{Kg}$ a Digital Weight scale (Detecto) with height was recorded to the nearest $0.5 \mathrm{~cm}$ using the same scale, and BMI was calculated as $\mathrm{Kg} / \mathrm{m}^{2}$. Weight was categorized according to BMI $(\mathrm{kg}) /(\mathrm{m})^{2}$ into, underweight $(<18.5)$, normal $(18.5<25)$, overweight $(25<30)$, class I obesity $(30<35)$, class II obesity (35) and class III obesity (40+). (8)

Other Data were collected by a questionnaire consisting of two sections and 15 items. Dietary habits data included: Family history of obesity, Practice Sports, Eating breakfast, No. of main meals/day, Preferred beverages, Frequency of drinking aerated beverages/day, Snacking per week, fast food per week, eating during watching TV. Social and Psychological situation data included: the availability of fast food frequently affects obesity, students feel that obesity was problem of them, Meals system, Social conditions, information about drugs used Weight Loss, the problems that caused you to obesity, describe your body, economic situation, suffering from diseases. All participants signed a consent letter before contributing in the research and were assured confidentiality.

\section{Statistical Analysis}

Data were analyzed using SPSS software, version 17.0. The Chi-squared test was used to assess the statistical 
significance of the association between BMI category and other variables. $p \leq 0.05$ was considered statistically significant.

\section{Results}

Distribution of students according to BMI is presented in Figure 1. Among the students, $27.4 \%$ were underweight and $47 \%$ were classified as normal. Overweight student's represents $16 \%$ and $9.6 \%$ were categorized obese.

Figures 2-4 show the general characteristics of the study sample the total number of study participants amounted to 240 . Those who practiced exercise sometimes $58.7 \%$ of the study sample and about $38.3 \%$ had positive family history of obesity. Almost $37 \%$ not suffering from disease and $27.4 \%, 20.8 \%$ and $14.8 \%$ suffering from headache, diabetes and joints pain respectively.

Table 1 demonstrates dietary habits of the study participants, $60.9 \%$ of students reported eating breakfast with

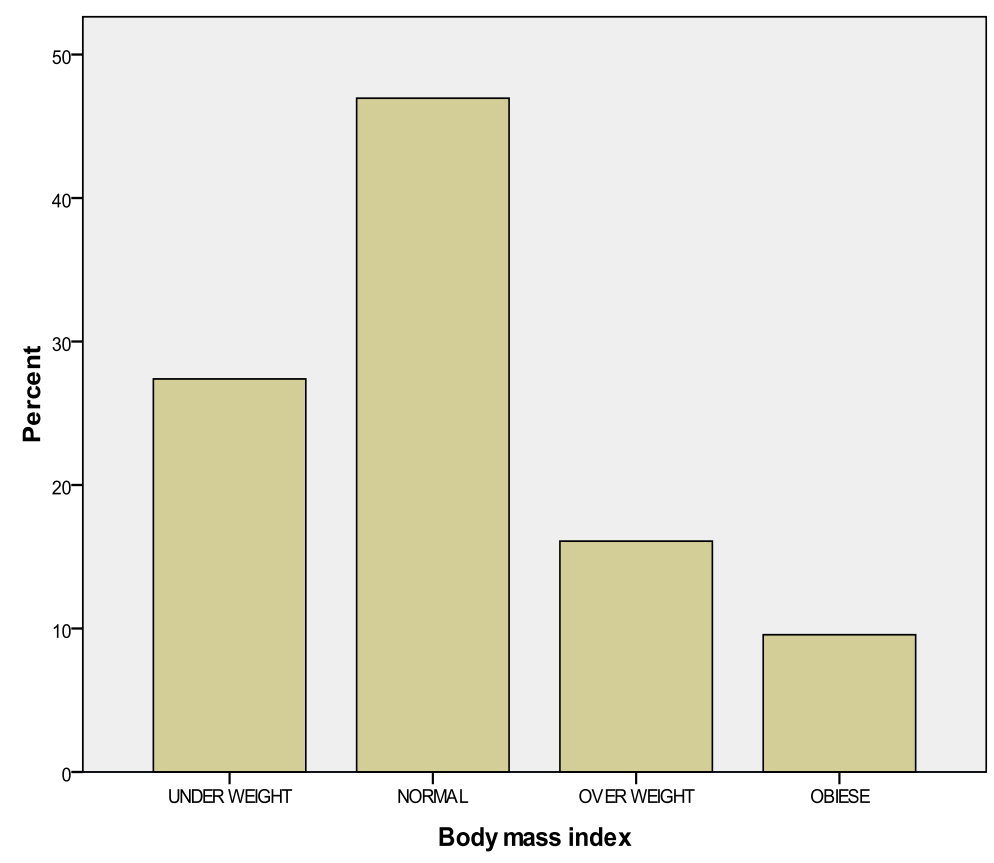

Figure 1. Distribution of students according to body mass index.

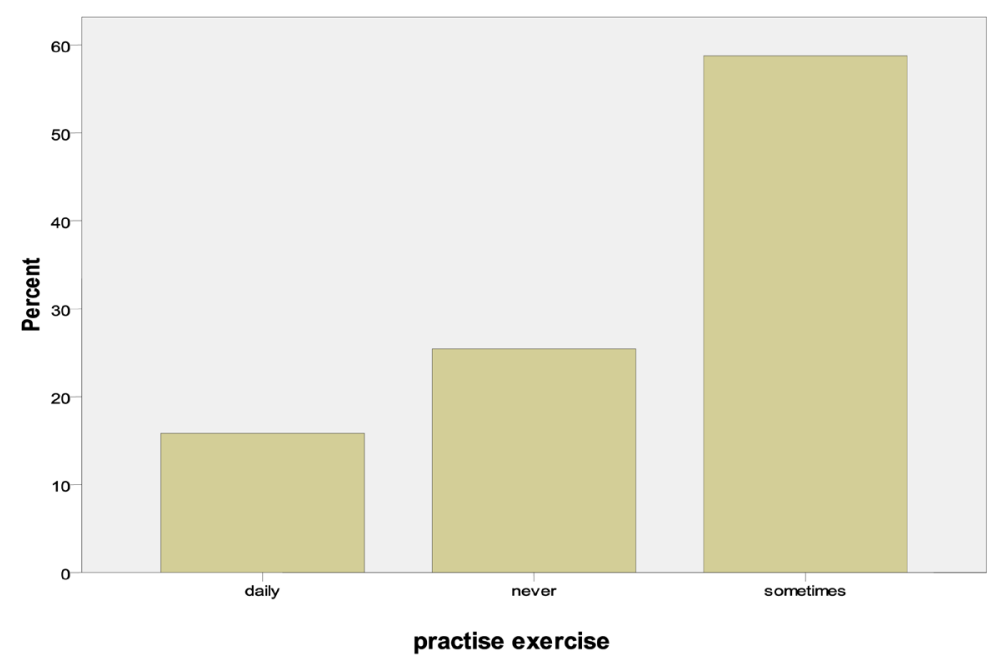

Figure 2. The Percentage of students according to physical exercise per day. 


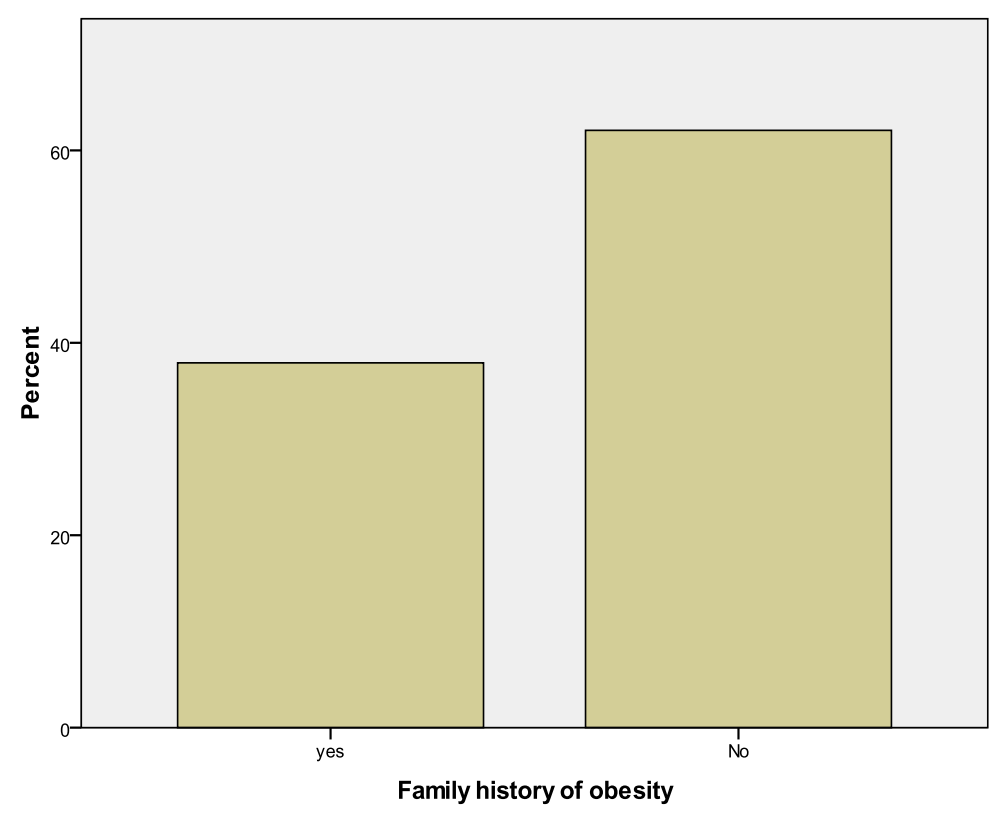

Figure 3. The Percentage of students according to family history of obesity.

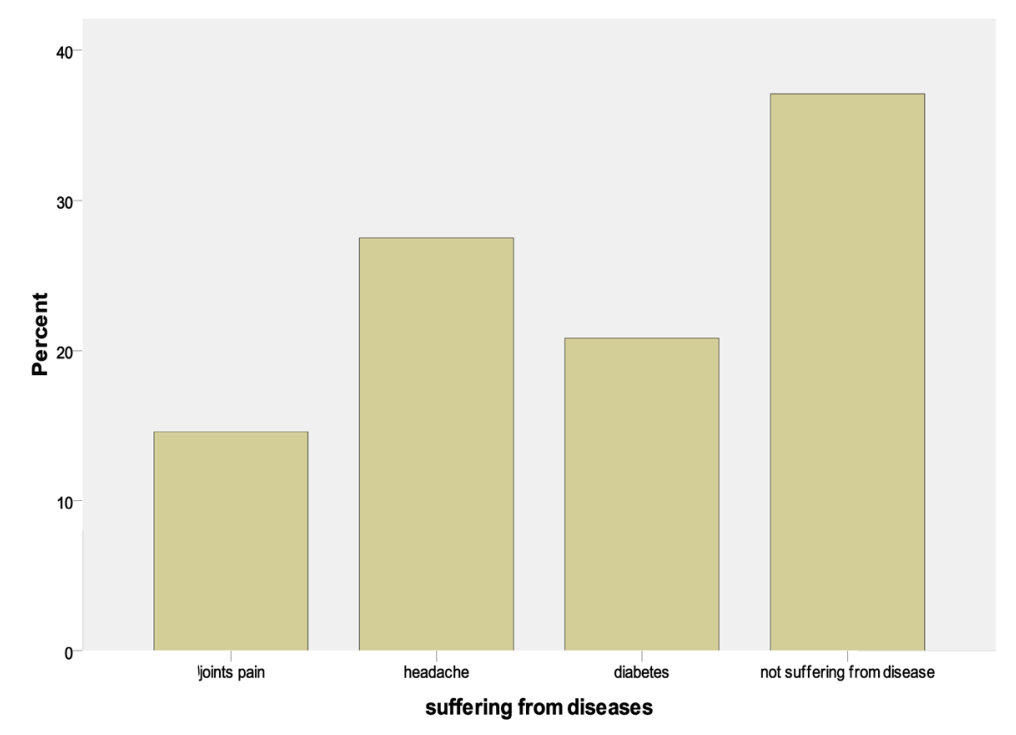

Figure 4. The Percentage of students according to suffer from diseases.

no significant relationship between The BMI categories and eating breakfast $(\mathrm{p}>0.05)$. More than half of studied sample ( $63 \%$ ) ate three meals per day, again with no significant variation between The BMI categories and Number of meals per day $(p>0.05)$. The majority of students preferred natural drinks $(68.7 \%)$ with no significant differences $(p>0.05)$ between BMI categories. On the other hand Frequency of drinking aerated beverages 3 or more per week was reported by $38.3 \%$ While the frequency of eating fast foods 3 or more times per week was reported by $41.3 \%$ and $50 \%$ reported eating fast foods one and two times per week and $8.7 \%$ of the students reported never eating fast foods per week with no significant differences $(p>0.05)$ between BMI categories. A few number from participants reported never eating snacks $(0.4 \%)$. It is worth mentioning that $84.8 \%$ of students reported eating snacks 3 or more times per week with no significant differences $(p>0.05)$ between BMI categories. More than half of sample had eating meals during watching TV with no significant differences $(p>0.05)$ between BMI categories.

Table 2 demonstrates social and Psychological situation of the study participants $63 \%$ of students feel that 
Table 1. Dietary Habits of the study sample $(n=240)$.

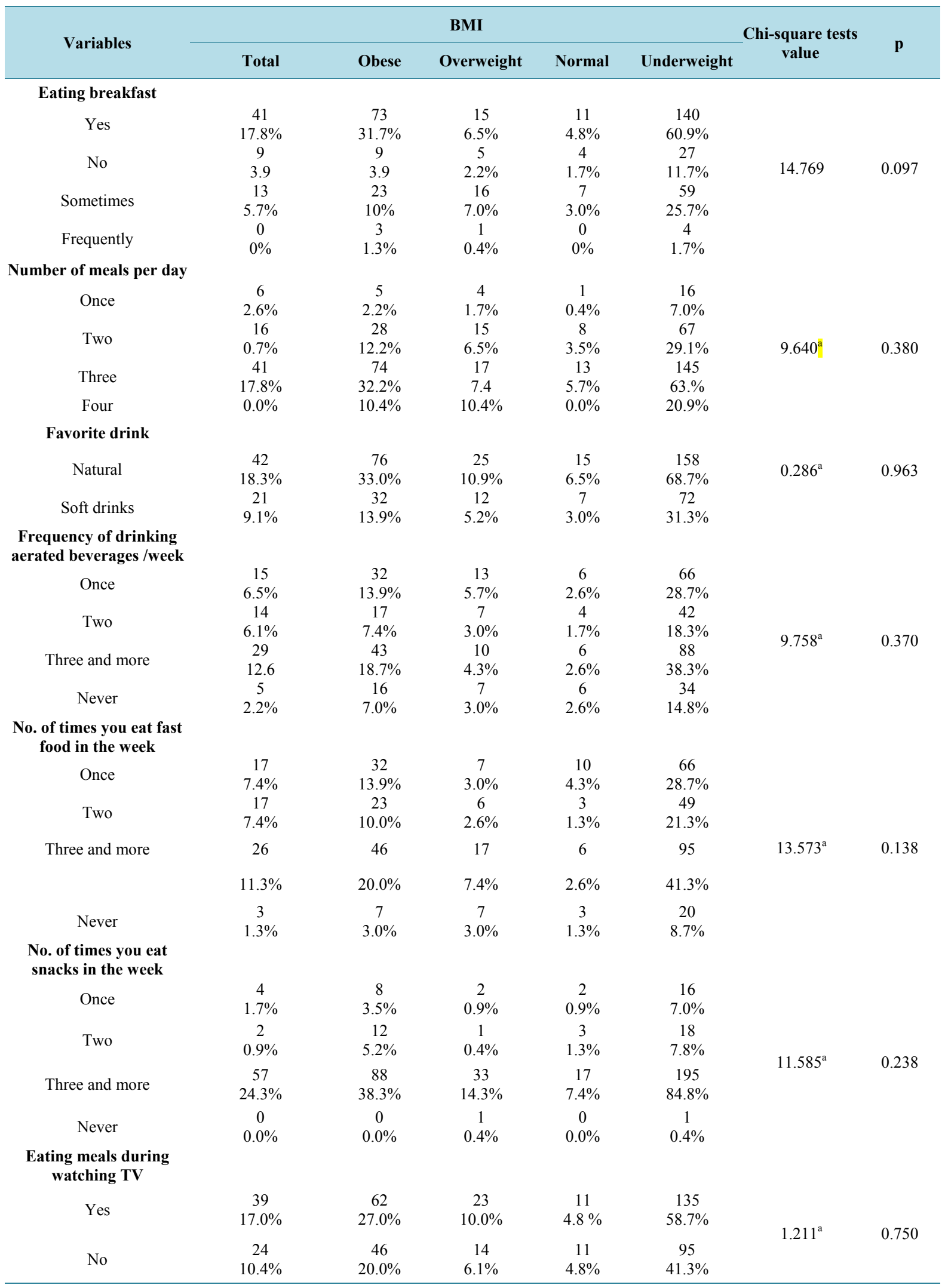


Table 2. Social and Psychological situation of the study sample $(\mathrm{n}=240)$.

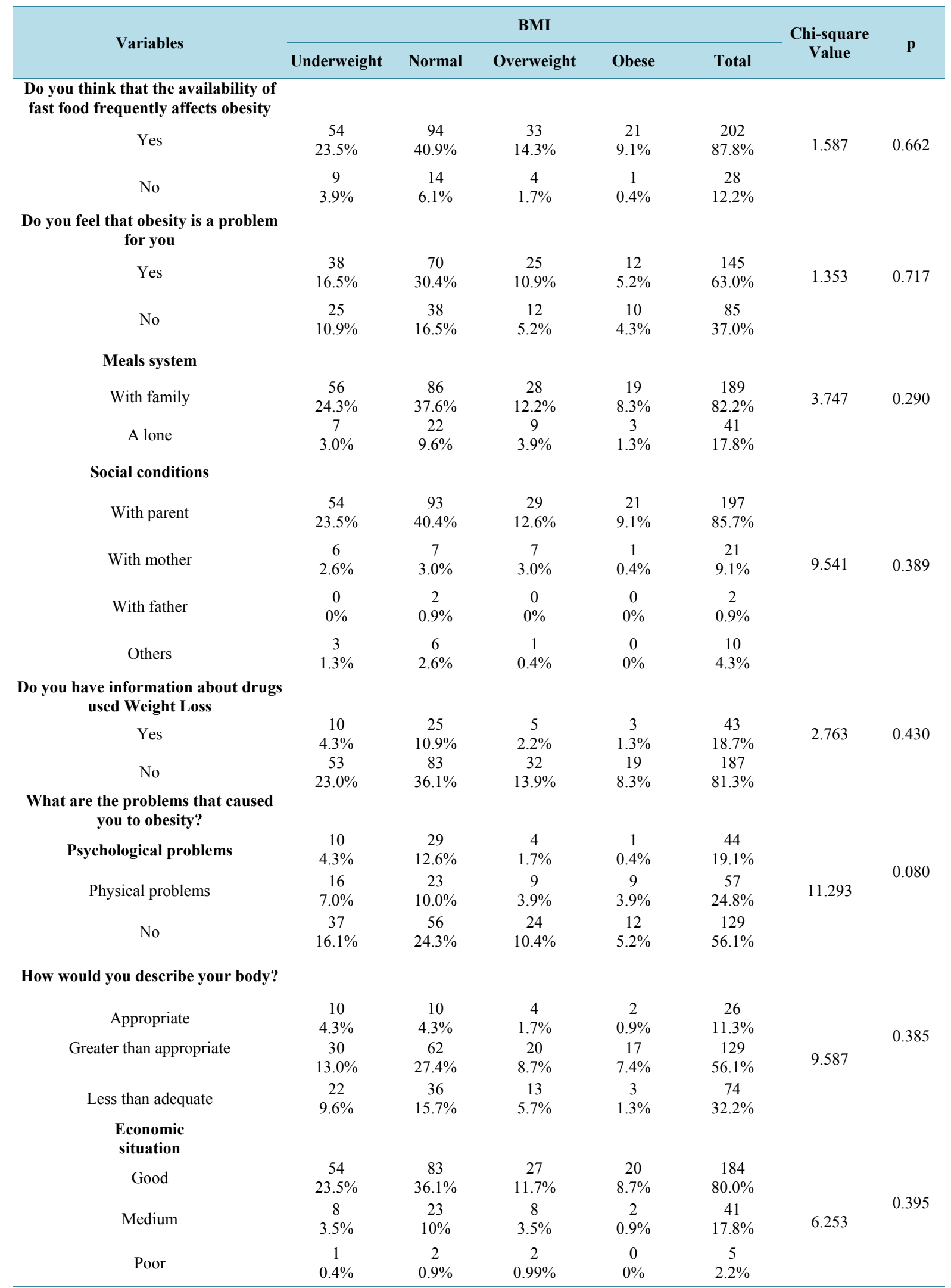


obesity was problem of them and $85.7 \%$ of students lived with parent but $4.2 \%$ of students lived with others. While $82.2 \%$ of students reported eating meals with their family. The minority of the students have information about the drugs used for weight loss (81.3\%). In total, $24.8 \%$ of students reported that obesity caused physical problems and $99.6 \%$ of students described their body less than appropriate while $32.2 \%$ of participants described their body greater than appropriate. The economic situation of students was $80 \%$ good, $17.8 \%$ medium and $2.2 \%$ poor.

\section{Discussion}

Our study showed that female students in this study, irrespective of BMI category had some bad eating habits including skipping breakfast ad frequency of drinking aerated beverage 3 or more times per week and eating snacks such as chocolate and chips per week and watching TV during eating meals. These sorts of dietary habits for students can lead to increase body weight in the future and are likely to become regular habits for them and their families. Our findings are in agreement with other studies regarding unhealthy dietary habits of female students. During adolescence hormonal changes accelerate growth in height. Growth is faster than at any other time in the individuals postnatal life except the first year so this may negatively or positively affect the consumption of food and dietary habits which may be related to the community [5]. The current data demonstrated that more than one third was the normal body weight. Over weight students represented $16 \%$ and $9.6 \%$ were categorized obese. These findings were consistent with the results of similar studies in some countries. In Iranian male college students were only $7.9 \%$ above the normal body weight [6]. That rate decreased to $2.9 \%$ among Chinese college students with a percentage of obesity as low as 0.4 [7]. While in Lebanon, the prevalence of overweight and obesity among male college students was 37.5\% and $12.5 \%$, respectively [8]. In Kuwait the corresponding percentages were $32 \%$ and $8.9 \%$ [9] while in the united states and the united Arab Emirates overweight and obese accounted for about $35 \%$ of the male college students [10]-[12]. The results of our study showed that most of the students reported drinking aerated beverages 3 or more times per week. The majority of students eat fast foods 3 or more times per week and $84.8 \%$ of students eat snacks such as chocolate and chips 3 or more per week and more than of sample had eating meals during watching TV. These dietary habits need to be corrected to using educational programs to promote healthy eating habits in KSA. On the other hand most of students take breakfast, eat three meals per day, eat with their families, and prefer natural drinks. These habits ought to be encouraged comparing our results with equivalent studies Lebanon and China [7] [8]. This study also indicated that there is no significant difference between the social characteristics data and BMI another study reported an association between socioeconomic factors and obesity and adolescents in primary and intermediate schools [13]. It is reported that watching $\mathrm{T}$ during family meals is associated with poorer dietary quality among adolescents and increased TV viewing is associated with increased caloric intake, consumption of higher fat food and lower intake of fruits and vegetables [11] [14] which is in line with our results.

\section{Conclusion}

Our results showed that there was no significant variation between BMI category and dietary habits but the dietary habits of the female students were unhealthy and most of students ate fast food for 3 times or more per week.

\section{Recommendations}

Increasing educational programs introduces healthy dietary concepts to improve the dietary habits of female students.

\section{Acknowledgements}

The authors would like to thank Dr. Manal Ahmed Abd ElRazek, stuff and Students medical clinic for her times and effort in measuring weight and height for BMI. The authors wish to thank the students who participated in the study.

\section{References}

[1] Rampersaud, G.C., et al. (2005) Breakfast Habits, Nutritional Status, Body Weight, and Academic Performance in 
Children and Adolescents. Journal of the American Dietetic Association, 105, 743-760.

[2] Heitmann, B.L., Erikson, H., Ellsinger, B.M., Mikkelsen, K.L. and Larsson, B. (2000) Mortality Associated with Body Fat, Fat-Free Mass and Body Massindex among 60-Year-Old Swedish Men-A 22-Year Follow-Up. The Study of Men Born in 1913. International Journal of Obesity and Related Metabolic Disorders, 24, 33-37. http://dx.doi.org/10.1038/sj.ijo.0801082

[3] World Health Organization. Global Database on Obesity and Overweight. http://www.who.int/mediacentre/factsheets/fs311/en/

[4] Susan, T. and Neela, B. (2014) Practice, Behavior, Knowledge and Awareness of Food Safety among Secondary \& Tertiary Level Students in Trinidad, West Indies. Food and Nutrition Sciences, 5, 1463-1481.

[5] Gex, et al. (2001) Pubertal Transitions, Perceptions of Being Overweight and Adolescent Psychological Maladjustment. Gender and Ethnic Difference, 64, 363-375.

[6] Nojomi, M. (2006) Najamabad Students: Obesity among University Students, Tehran, Iran. Asia Pacific Journal of Clinical Nutrition, 15, 516-520.

[7] Sakamaki, R., Toyama, K., Amamoto, R., Liu, C.J. and Shinfuku, N. (2005) Nutritional Knowledge Food Habits and Health Attitude of Chinese University Student. Across Sectional Study. Nutrition Journal, 4, 4. http://dx.doi.org/10.1186/1475-2891-4-4

[8] Yahia, N., Achkar, A., Abdallah, A. and Rizk, S. (2008) Eating Habits and Obesity among Lebanese University Students. Nutrition Journal, 7, 32. http://dx.doi.org/10.1186/1475-2891-7-32

[9] Al-Isa, A.N. (1999) Obesity among Kuwait University Students: An Explorative Study. Journal of The Royal Society for The Promotion of Health, 119, 223-227. http://dx.doi.org/10.1177/146642409911900404

[10] Huang, T.T., Harris, K.J., Lee, R.E., Nazir, N., Born, W. and Kaur, H. (2003) Assessing Overweight, Obesity, Diet, and Physical Activity in College Students. The Journal of the American College of Nutrition, 52, 83-86. http://dx.doi.org/10.1080/07448480309595728

[11] Lowry, R., Galuska, D.A., Fulton, J.E., Wechsler, H., Kann, L. and Collins, J.L. (2000) Physical Activity, Food Choice, and Weight Management Goals and Practices among US College Students. American Journal of Preventive Medicine, 18, 18-27. http://dx.doi.org/10.1016/S0749-3797(99)00107-5

[12] Musaiger, A.O., Lloyd, O.L., Al-Neyadi, S.M. and Bener, A.B. (2003) Lifestyle Factors Associated with Obesity among Male University Students in the United Arab Emirates. Nutrition and Food Sciences, 33, 145-147. http://dx.doi.org/10.1108/00346650310488480

[13] Alsaif, M.A., Hakim, I.A., Harris, R.B., Alduwaihy, M., Al-Rubeaan, K., Al-Nuaim, A.R. and Al-Attas, O.S. (2002) Prevalence and Risk Factors of Obesity and Overweight in Adult Saudi Population. Nutrition Research, 22, 1243-1252. http://dx.doi.org/10.1016/S0271-5317(02)00439-6

[14] Freedland, S.J., Wen, J., Wuerstle, M., Shah, A., Lai, D., Moalej, B., Atala, C. and Aronson, W.J. (2008) Obesity Is a Significant Risk Factor for Prostate Cancer at the Time of Biopsy. Urology, 72, 1102-1105.

http://dx.doi.org/10.1016/j.urology.2008.05.044 